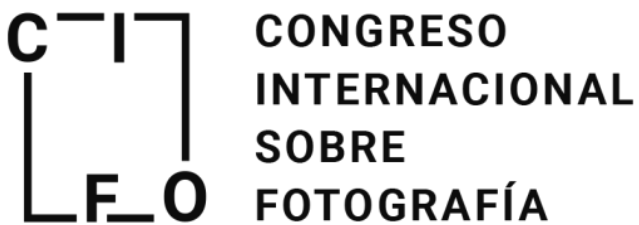

Congreso Internacional sobre Fotografía

UPV, 5 y 6 octubre 2017

Doi: http://dx.doi.org/10.4995/CIFo17.2017.6773

ISBN: 978-84-9048-604-7

\section{Charles Clifford y José Martínez Sánchez: hacia una expresión de la arquitecura plenamente fotográfica.}

Pablo Fernández Díaz-Fierros

Escuela Técnica Superior de Arquitectura de la Universidad de Sevilla, contacto@pablodiazfierros.com

\begin{abstract}
Resumen
Con el propósito de extraer conclusiones en torno a la aportación de innovaciones estéticas en la comunicación visual de la arquitectura en la décadas de los años cincuenta y sesenta del siglo XIX en España, utilizo en el proceso de mi investigación la metodología comparativa de vistas similares tomadas por distintos autores y su conceptualización a esquemas básicos de composición. Fotografias, que tras una detenida operación de lectura, muestran episodios narrativos que me ofrecen la posibilidad de detectar valores plásticos en sus composiciones, superando el planteamiento mimético como fin último del reciente procedimiento de captar imágenes y encaminándose hacia un nuevo estadio de la expresión fotográfica. La comparación de encuadres semejantes sobre un mismo motivo mediante una selección de fotografías tomadas por Clifford y Martínez Sánchez es un modelo de estudio que se avanza en este artículo con el análisis de un caso ejemplar.
\end{abstract}

Palabras clave: fotografía, arquitectura, siglo XIX, representación, composición.

\begin{abstract}
With the aim of forming conclusions regarding the incorporation of aesthetic innovations in the visual communication of architecture in the 50s and the 60s in 19th century Spain, I use in the development of my doctoral research the comparative methodology of similar views taken by different photographers, and the reduction of these to basic compositional schemes. After a careful examination, the exemplary photographs reflect narrative episodes which open the door to detecting aesthetic values in their composition, thereby improving on the mimetic concept as the ultimate goal of the recent procedure of capturing images and striving towards a new level of photographic expression. A study of this methodology is presented in this article by analyzing one exemplary case, where similar frames for the same architectural model are compared, using a selection of pictures taken by Clifford and Martinez Sánchez.
\end{abstract}

Keywords: photography, architecture, 19th century, representation, composition. 
Charles Clifford (Newport, Gales del Sur, $1819^{1}$ - Madrid, 1863) máximo exponente de la fotografía de arquitectura en España durante la segunda mitad del siglo XIX, llega a Madrid en el otoño de $1850^{2}$ presentándose en la prensa como aeronauta. Tras su participación en diversas ascensiones con globos aerostáticos en espectáculos populares con éxito desigual, inicia su carrera como fotógrafo aprovechando la escasa presencia local de diestros en el oficio. No tarda en contactar con los ambientes burgueses, nobles y artísticos de la capital, alcanzando en pocos años un notable prestigio, no sólo por el carácter testimonial de sus tomas y su pericia en el manejo de las modernas técnicas importadas de Europa, sino por el original lenguaje visual de sus fotografías, cuya belleza plástica, lejos de entrar en competencia con el contenido documental, lo complementa, enriqueciendo el mensaje.

En la nota necrológica del fallecimiento de Clifford publicada en la revista El Museo Universal, su director, Nemesio Fernández Cuesta, no duda en calificarlo como "artista notable y fotógrafo de los más adelantados en su arte" ${ }^{3}$. Efectivamente, sus fotografías ejemplares son mucho más que el registro de una realidad arquitectónica porque tienen esa componente estética que las distinguen de un simple documento. No basta con el contenido representado porque no son simples pruebas testimoniales, se expanden más allá de sus bordes, se salen de los límites del papel y, en ocasiones, se sitúan fronterizos entre el documento y el objeto plástico. Sería aventurado considerar como estrictamente artísticas las fotografías de Clifford, pero sí se detectan episodios narrativos e interpretativos porque para él la creación fotográfica no es sólo la consecuencia directa de un procedimiento técnico bien resuelto, sino que es también el resultado del uso de códigos estéticos integradas en sus composiciones que favorecen la expresión por encima de la documentación. La vista inédita de un río con una barca [fig.1], cuya autoría atribuyo a Clifford por su estilo y tamaño, viene a desvelar la capacidad y la consideración de la fotografía como un nuevo medio de expresión personal, buscando nuevos planteamientos y lenguajes difíciles de concebir desde el encargo institucional. Sólo un amante de la fotografía, como Antonio de Orleans, aceptaría de buen grado estas innovaciones visuales.

\footnotetext{
${ }^{1}$ Según FONTANELLA, L. (1999). Clifford en España: un fotógrafo en la corte de Isabel II. Madrid: El Viso, p.25.

${ }^{2}$ BULlOUGH AINSCOUGH, R. (2015), lo sitúa un mes antes de su llegada a España en Burdeos en una ascensión benéfica, en "Globos y caballos" en Revista Internacional de la Imagen, Volumen 2, № 2, p.135.

${ }^{3}$ El Museo Universal, Madrid, 11 de enero de 1863, p.1, Biblioteca Nacional de España.
} 


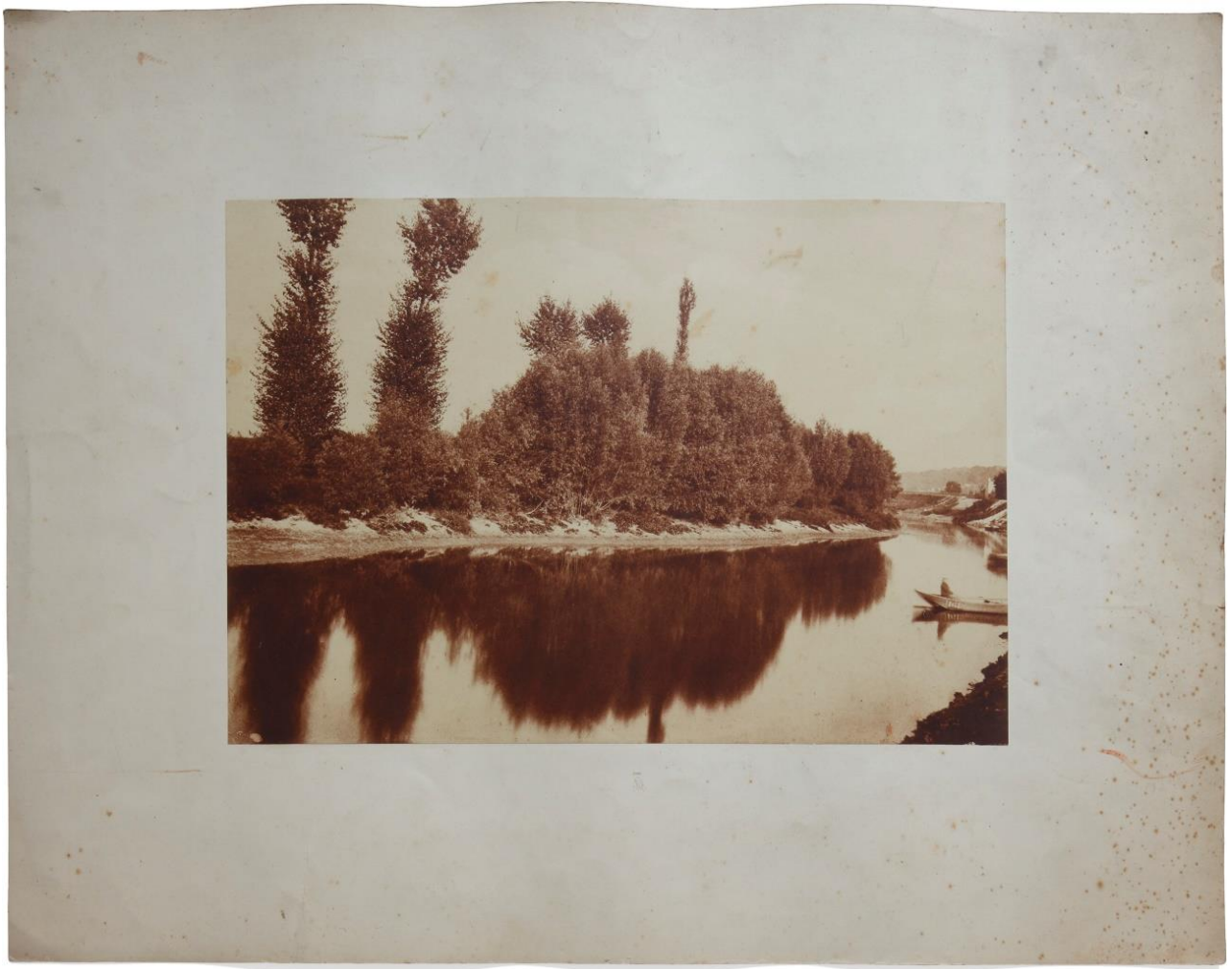

Fig. 1. Atrib. Clifford, Charles, s.t. Río con barca, Sin identificar el lugar y la fecha, Negativo papel, Papel fotográfico $27,4 \times 39,8 \mathrm{~cm}$. sobre cartulina $48 \times 62,1 \mathrm{~cm}$. con sello seco de Antonio de Orleans, Duque de Montpensier, Fotografía inédita, Colección Fierros.

José Martínez Sánchez (Bicorp, Valencia, 1807- Valencia, 1874), inicia su negocio de fotografía en fechas próximas a la aparición de Clifford en la escena fotográfica madrileña, y allí ejerció su actividad profesional probablemente hasta $1869^{4}$, año en el que se traslada a Valencia para continuar su profesión. Fotografió con gran destreza técnica y esmeradas composiciones arquitecturas del pasado y del presente, con especial dedicación a las obras públicas (faros, puentes, puertos, infraestructuras ferroviarias, carreteras, desmontes, etc.). Como retratista está documentada su actividad en Madrid al menos desde 1851, pues en la Colección Castellano hay una fotografía suya del duque de Feria fechada en ese año ${ }^{5}$. Posaron frente a él un importante número de personas, en sus más variadas posiciones sociales, económicas y profesionales, desde miembros de la corte y del gobierno hasta los oficios más populares. Una buena parte de esos retratos, dispuestos en álbumes, llegaron a manos del pintor Manuel Blas Rodríguez Castellano y de la Parra, más conocido como Manuel Castellano (Madrid, 1826 - Madrid, 1880), personaje central en la historia del coleccionismo fotográfico en España y responsable de la homónima colección antes citada. Según las investigaciones más recientes ${ }^{6}$, la ausencia de un criterio claro en la ordenación de los álbumes y en la temática de las fotografías hace pensar que se trataban de muestrarios de las fotografías del estudio de Martínez Sánchez y sus sucesores y no de una colección fotográfica realizada por el pintor.

\footnotetext{
${ }^{4}$ Fecha tomada de RODRÍGUEZ MOLINA, M. J. y SANCHÍS ALFONSO, J. R. (2014). Una nueva visión de la fotografía española: la obra de José Martínez Sánchez, 1807-1874, Valencia: Railowsky, p.102.

${ }^{5}$ Ref: 17/LF/62 (ER 528), f.13. Biblioteca Nacional de España.

${ }^{6}$ RODRÍGUEZ MOLINA, M.J. y SANCHÍS ALFONSO, J.R. op.cit, p. 130.
} 
Seducido por la fotografía, Castellano se retrató entre 1853 y 1869 más de treintena y seis veces ${ }^{7}$ bajo un constante juego de experimentación frente a la cámara, consciente de la fuerza visual que el nuevo medio ponía a su alcance. En algunas de esas tomas el pintor aparece en posturas poco habituales y atrevidas, buscando una expresión genuinamente fotográfica frente a los repetitivos y previsibles retratos al uso, que carecían de cualquier intención estética, haciendo posar al modelo sin detener la mirada en su personalidad, sin prestarle atención, sin dejarlo actuar para que ofrezca algo interesante, sin la más mínima inquietud creativa, sólo como frías representaciones que se limitaban a dejar constancia de la presencia del modelo dentro de la normas y los valores culturales de la época. No importaba quién era el retratado, ni su estatus social ni su profesión, pues siempre se situaba igual frente a la cámara, integrado en una escenografía generalmente adornada con una variedad de elementos decorativos que hoy nos parecen de muy mal gusto: un forillo, un papel pintado, una balaustrada, una columna, un jarrón, una cortina o los indispensable muebles: una silla, una mesa, un velador, etc. Todos ellos elementos compositivos que, debiendo ser secundarios, tenían tanto peso visual en la representación fotográfica como el propio retratado.

Esta producción en serie de fotografías sin alma ni personalidad era el argumento que utilizaban los artistas para defender las virtudes del retrato pictórico, negando el papel interpretativo del fotógrafo, que era considerado exclusivamente un operario que manejaba con destreza y técnica una máquina de captar imágenes. Pero hay buenos ejemplos que demuestran que de la convivencia entre pintores y fotógrafos surgen intercambios y complicidades que exploran nuevas vías de expresión, no sólo del contenido representado, sino de su interpretación. De la afinidad entre Castellano y Martínez Sánchez, amigos al menos desde 1850, surgen retratos poco habituales, sencillos y directos, nada barrocos, sin artificios, sin aparente premeditación, que obvian la imagen idealizada de las cartas de visita y exploran nuevos horizontes en el recién inaugurado lenguaje fotográfico. Un ejemplo claro, y a primera vista desconcertante, es la imagen que muestra a Castellano tirado sobre el suelo enmoquetado del estudio del fotógrafo [fig.2], contenido en un encuadre que sacrifica las encorsetadas formas establecidas en favor de la espontaneidad. La situación, que para la mayoría de los fotógrafos no merecería ni un solo negativo, traslada al espectador de un modo directo el carácter inquieto y activo que caracterizó al pintor madrileño, sin complacencias ni adornos. Probablemente este retrato se realizó después de uno más formal ${ }^{8}$ en el que se le exigió aguantar inmóvil el disparo acompañado por algún mueble de apoyo y, como las cámaras eran técnicamente limitadas, la espera se pudo alargar. No es descabellado pensar que tras la sesión de posado llegó el relajamiento y con él la espontaneidad, y es precisamente en ella donde radica la potencia de este retrato, que no necesita arreglos ni accesorios, basta con la sinceridad y la sencillez.

\footnotetext{
${ }^{7}$ ONFRAY, S. (2016). "Tras la imagen del coleccionista: influencia y protagonismo de Manuel Castellano en el desarrollo y la conservación del retrato fotográfico en Madrid” en De Arte, nº 15, Madrid: Universidad Complutense, p.233.

${ }^{8}$ En la Colección Castellano, tomo 14, página 18, signatura: 17-LF/59 (11), Madrid, Biblioteca Nacional de España, figura un retrato de medio cuerpo que, por el aspecto físico y por la vestimenta, pudo realizarse durante la misma sesión fotográfica.
} 
Además del contenido representado y del mínimo repertorio utilizado para contarlo, este retrato aporta también innovaciones en la utilización de la línea ${ }^{9}$ inclinada como agente activador de la composición. Colocarla en posición horizontal hubiese sido el gesto más inmediato, el que respondiera a las expectativas, proyectando una sensación de serenidad y reposo, pero Martínez Sánchez la deja caer, abandonando la estabilidad y agudizando la tensión. El desequilibrio mediante la inclinación de la horizontal es un recurso que, si fuera intencionado, resulta sorprendente en este estadio de la fotografía pues intensifica la filosofía irreverente de la toma, aportándole ciertas dosis de dinamismo que encajan con la personalidad del retratado.

Estos hechos, unidos a la evidente falta de nitidez, serían motivos suficientes para descartar esta imagen por técnicamente imperfecta y por incumplimiento de los esquemas formales "oficiales" en la práctica del retrato fotográfico que imponían las modas y la clientela en el periodo central del siglo XIX en España. Sin embargo, Castellano la recoge en uno de los álbumes de su colección, probablemente porque está llena de verdad y se reconoce en ella.

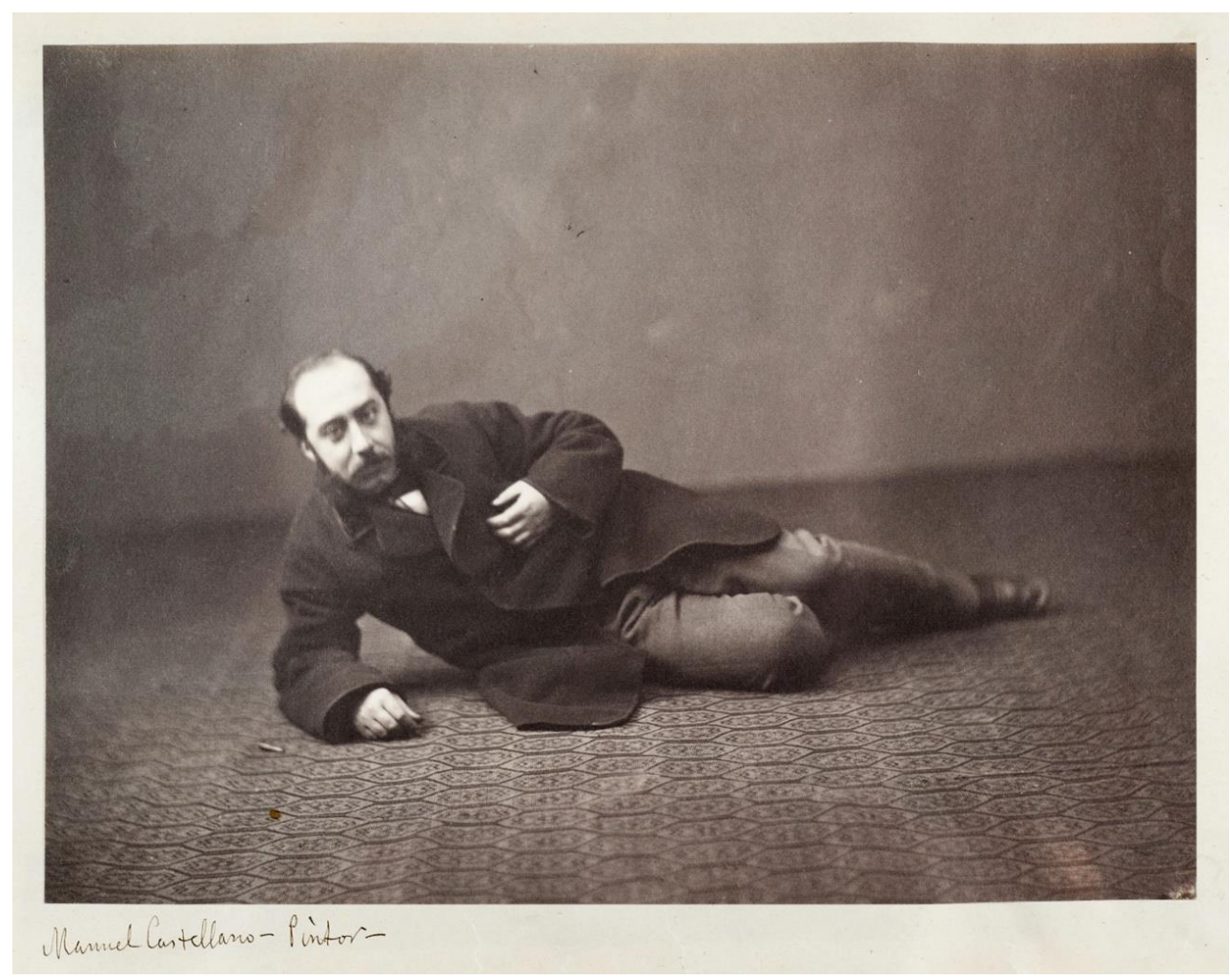

Fig. 2. MARTÍNEZ SÁNCHEZ, José, Fotografias recogidas por el pintor Manuel Castellano entre 1857 y 1869, Retrato de Manuel Castellano, Tomo 11, signatura: 17-LF/56 (82), papel fotográfico 14,5 x 19,5 cm. Madrid, Biblioteca Nacional de España.

\footnotetext{
${ }^{9}$ Aunque la fotografía trabaja con valores tonales y no con contornos propiamente dichos, en el proceso de análisis gráfico que más adelante detallo, propongo traducir las imágenes a geometrías básicas y, en este caso, del encuentro entre el plano del suelo y el de la pared surge la línea.
} 
La fotografía que nos presenta al pintor Dionisio Fierros Álvarez ${ }^{10}$ (La Ballota, Asturias, 1827Madrid, 1894), posando de pie elegantemente vestido sobre la inconfundible moqueta y el característico fondo liso del estudio de Martínez Sánchez [fig.3] está cargada de intención y de concepto. El fotógrafo se libera de las forzadas escenografías atestadas de elementos decorativos y deja de un modo deliberado y claramente visible sobre el suelo uno de los más característicos: la cortina. No creo que sea una casualidad ni un accidente, sino un posicionamiento de Martínez Sánchez (en sintonía con Fierros) frente a los retratos muy construidos, un ejercicio de prescindir de todo aquello que distrae la atención, de quitar lo que sobra, lo que resta, lo que no es propio del retratado y, por tanto, no lo define. En definitiva, una búsqueda de nuevas vías de expresión en las que la simplicidad es la base de la eficacia visual, negando el retrato como una acumulación de elementos que compiten en jerarquía y significado con el verdadero protagonista.

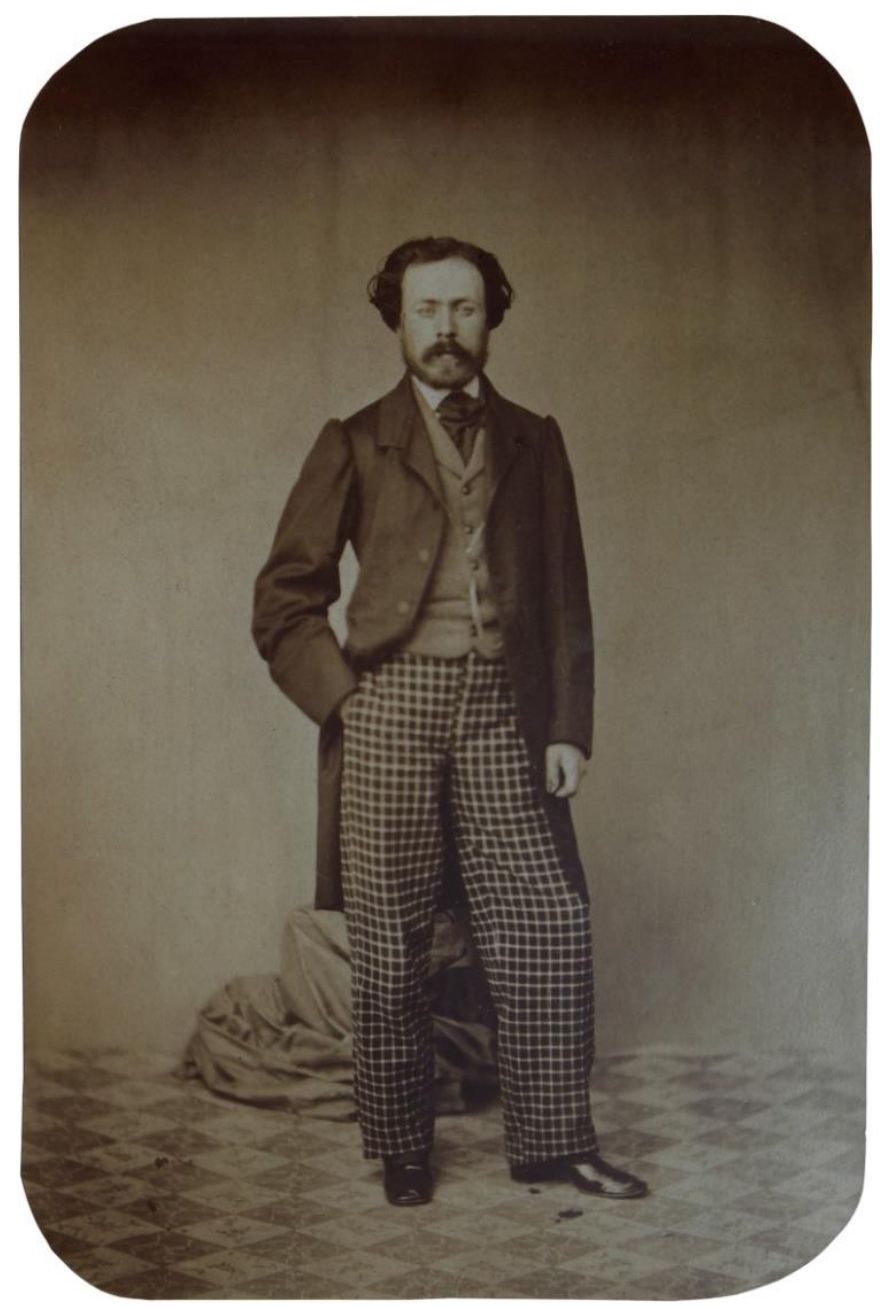

Fig. 3. MARTÍNEZ SÁNCHEZ, José. s.t. Retrato de Dionisio Fierros, Madrid, ca.1861, Papel a la albúmina, 20,4 x 13,5 cm, Fotografia inédita, Colección Fierros.

\footnotetext{
${ }^{10}$ Además de compañero y amigo cercano de Castellano desde que coincidieron en su época de formación artística en Madrid, mantuvo una productiva relación amistosa y profesional con los mejores fotógrafos que operaban en la capital, como Martínez Sánchez, Eusebio Juliá, Jean Laurent y sobre todo, Charles Clifford.
} 
Es preciso indicar que estos retratos tan interesantes, y no me refiero exclusivamente a los dos ejemplos anteriores, sino a todos aquellos que evidencian una búsqueda de nuevos planteamientos sin someterse a las disciplinas impuestas, surgen en la mayoría de las ocasiones de una asociación amistosa y profesional entre pintores y fotógrafos, o lo que es lo mismo, entre el mundo del arte y el de la fotografía, episodio que contradice la extendida idea de la rivalidad entre ambas disciplinas. No es casual que Castellano y Fierros sean los protagonistas de algunos casos sobresalientes, pues eran mucho más que simples clientes que acudían al reclamo del retrato de rigor; eran personajes con una actitud renovadora, curiosos, interesados por las novedades artísticas que llegaban de Europa y ávidos de nuevas experiencias estéticas. Su fructífera relación y buen entendimiento con los mejores fotógrafos que operaban por Madrid en los años cincuenta y sesenta del siglo XIX -Martínez Sánchez con Castellano y Clifford con Fierros- no sólo dio lugar a espléndidas colecciones ${ }^{11}$, también facilitó un constante intercambio de inquietudes y experiencias estilísticas aplicables al medio fotográfico, especialmente en las tomas exteriores, donde la selección especial, la organización y la jerarquía de los elementos que la configuran juegan un papel determinante en la significación plástica, logrando extraer un orden estético de una configuración existente. Es por ello las fotografías ejemplares de arquitecturas monumentales, obras públicas y paisajes que toman Clifford y Martínez Sánchez se abren con todos sus matices, y no por la transmisión de la realidad arquitectónica, sino por la visión que de ella nos ofrecen sus autores.

La comparación de las dos fotografías del Puente del Diablo es muy productiva como procedimiento analítico de indagación sobre los códigos narrativos de representación que utilizan Martínez Sánchez y Clifford, y resulta interesante por los diferentes posicionamientos a la hora de enfrentarse a una misma arquitectura. La vista que registra Clifford [fig.4] entre 1856 y 1858, según fechas respectivas del Museo Metropolitano de Arte de Nueva York ${ }^{12}$ y de Lee Fontanella ${ }^{13}$, es una fotografía de gran fuerza visual, muy técnica, sin desenfoques, tomada desde el punto de vista del espectador que pasea por la orilla del río Llobregat y que desprende la serenidad y tranquilidad que se debía respirar en ese ambiente, al que nos traslada de un modo casi idílico. Está hecha a plena luz del día, con un sol alto que produce un contraste que subraya y pone en valor lo tectónico del puente, con la casita de diseño infantil con tejado a dos aguas como punto fuerte visual y las montañas del fondo perfectamente encuadradas bajo el arco ojival central. Compositivamente es rigurosa, estática y de un marcado carácter lineal, con una tendencia a la geometrización con las líneas que definen de las orillas del río y el perfil del puente como quebrada línea de fuerza muy marcada que concentra lo esencial de la arquitectura fotografiada. A mi parecer, explica muy bien la construcción que se prentende comunicar pero sin mostrarla en su totalidad, gracias a la selección del punto de vista en combinación con un momento temporal donde la obra se nos presenta en su mayor potencial expresivo. La luz es una de las protagonistas de esta fotografía, logrando transformar el Puente del Diablo en un puro fenómeno

\footnotetext{
${ }^{11}$ Un detallado estudio que preparo en paralelo a esta investigación dará próximamente visibilidad a la colección Fierros, un conjunto fotográfico inédito de formidable valor que ha permanecido fuera del conocimiento público almacenado en una casa de los descendientes del pintor.

${ }^{12}$ http://www.metmuseum.org/art/collection/search/265920

${ }^{13}$ FONTANELLA, L. op.cit, p.158.
} 
óptico. La habilidad de Clifford para poner en acción los elementos precisos da como resultado una fotografía equilibrada y sobre todo "fácilmente legible" por la economía estructural y por la claridad de los significados. No me refiero a una elementalidad formal, el concepto de economía estructural alude al uso justo de las energías suscitadas por la puesta en acción de los elementos: el borde del río, el puente, el personaje femenino y las montañas.

Frente a la majestuosidad del puente aparece la empequeñecida figura de una mujer con una buena definición en posición centrada en el plano medio y en la zona inferior del encuadre, aportando a la composición un punto inmediato de referencia que capta la atención del espectador que contempla la fotografía. No hay intención de retratarla, Clifford la utiliza de modo deliberado como factor compositivo que acompaña al discurso que pretende trasladar: la poderosa escala de la infraestructura monumental. No es una anécdota ni una casualidad la presencia humana bajo el arco central, sino una intención del fotógrafo de proporcionar un punto de referencia escalar, pues de la escala y las proporciones dependen en buena parte las virtudes de esta arquitectura. Otra carcaterística de este elemento compositivo puntual es su naturaleza dinámica; en este caso, debido a su ubicación y nitidez, aporta a la composición estabilidad y serenidad, acentuando la soledad de la escena. No cabe duda que sin la inclusión del personaje esta fotografía sería menos sugestiva.

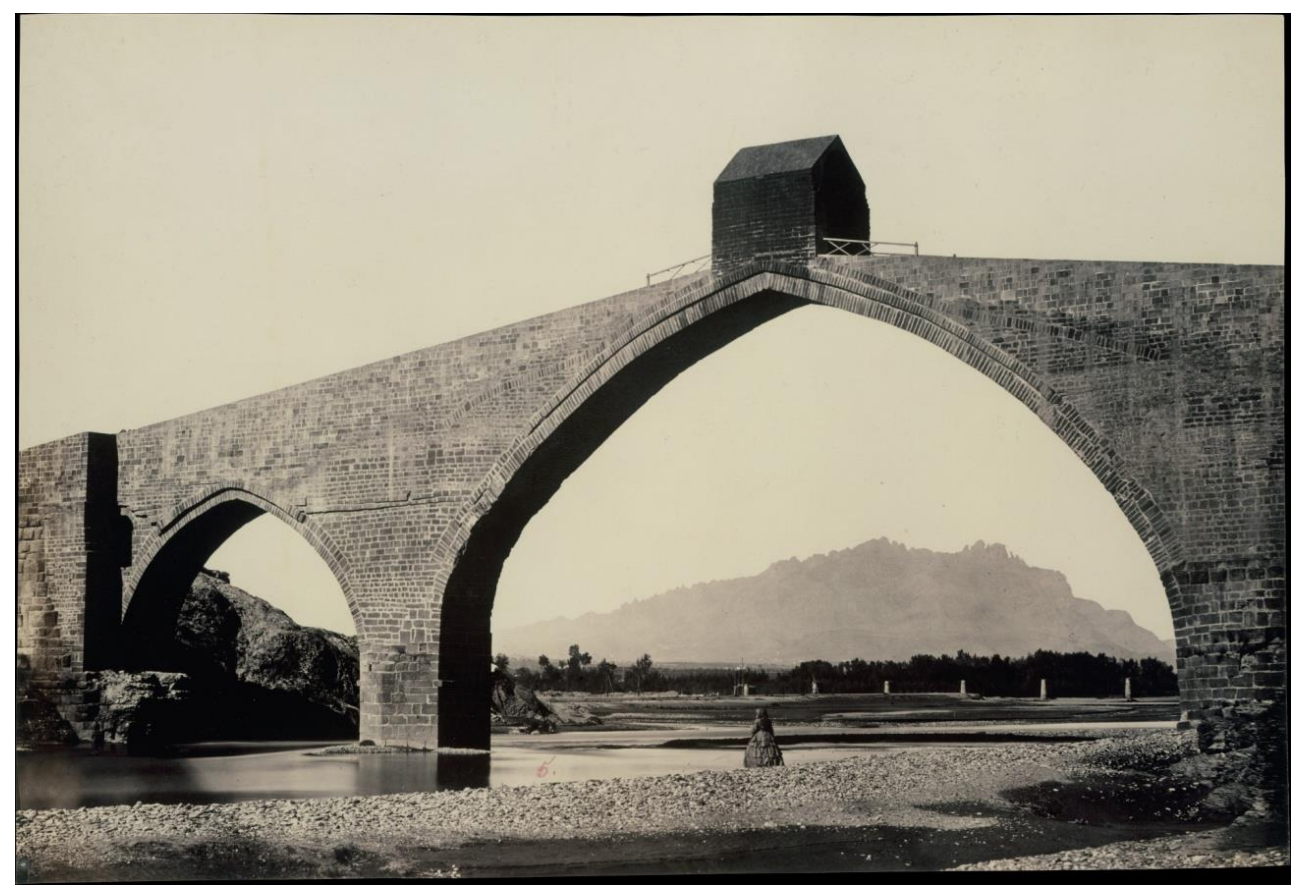

Fig. 4. CLIFFORD, Charles. Puente del Diablo, Martorell, ca.1856, Negativo cristal, Papel a la albúmina, 28,4 x 41,5 cm., Numerada "5" en el reverso mediante anotación manuscrita a lápiz rojo, Museo Metropolitano de Arte, Nueva York, Referencia 1988.1052.

Sin embargo, la mujer no aporta significado a la imagen, pues no nos habla del contexto rural en el que se tomó la fotografía. Según Lee Fontanella ${ }^{14}$ la figurante pudiera ser Jane Clifford, esposa del

\footnotetext{
${ }^{14}$ FONTANELLA, Lee, op.cit. p.90.
} 
fotógrafo y mujer aburguesada cuya vestimenta se alejaría bastante de la indumentaria humilde de las lugareñas. Debido a esa complicidad, es muy probable que exista una planificación de la escena, un diseño previo nada casual o incluso que Clifford hubiera anticipado la imagen en su cabeza y la mujer saliese al encuentro en el lugar pactado. Se desprende de este análisis una intencionalidad más allá del mero interés documental, incorporando pequeñas dosis narrativas, especialmente notables con la inclusión de la figura humana como elemento clave en la composición de sus fotografías.

La fotografía del mismo puente que toma José Martínez Sánchez [fig.5] once años después es similar a la de Clifford en su contenido representado, pero distinta en la articulación de los elementos que la conforman. El punto de vista seleccionado, alto y lejano, nos aporta más datos sobre el contexto pero le resta protagonismo al elemento principal, que en algunas zonas se fusiona con las montañas. Entran más atributos no arquitectónicos con peso en la selección espacial, como el río, que aporta profundidad y por tanto tensión compositiva, frente a la fotografía de Clifford, mucho más plana. La casita que corona el puente, maclada con las montañas del fondo, pierde fuerza en una coincidencia geométrica no deseable que le resta fuerza a este elemento tan característico. De modo irrelevante incorpora la figura humana mediante dos personajes visibles sobre la base de rodaje del puente, aunque con poco peso dentro de la composición. Es una fotografía menos técnica que la de Clifford, pues se desequilibra hacia la izquierda produciendo cierta incomodidad, como si faltase alguna fuerza que la enderezase (aunque a veces este recurso pueda tener interés, como en el retrato de Castellano anteriormente expuesto) y con menos intencionalidad arquitectónica. El momento temporal de la toma, con la luz rasante, le da un aire fantasmal que la llena de misterio.

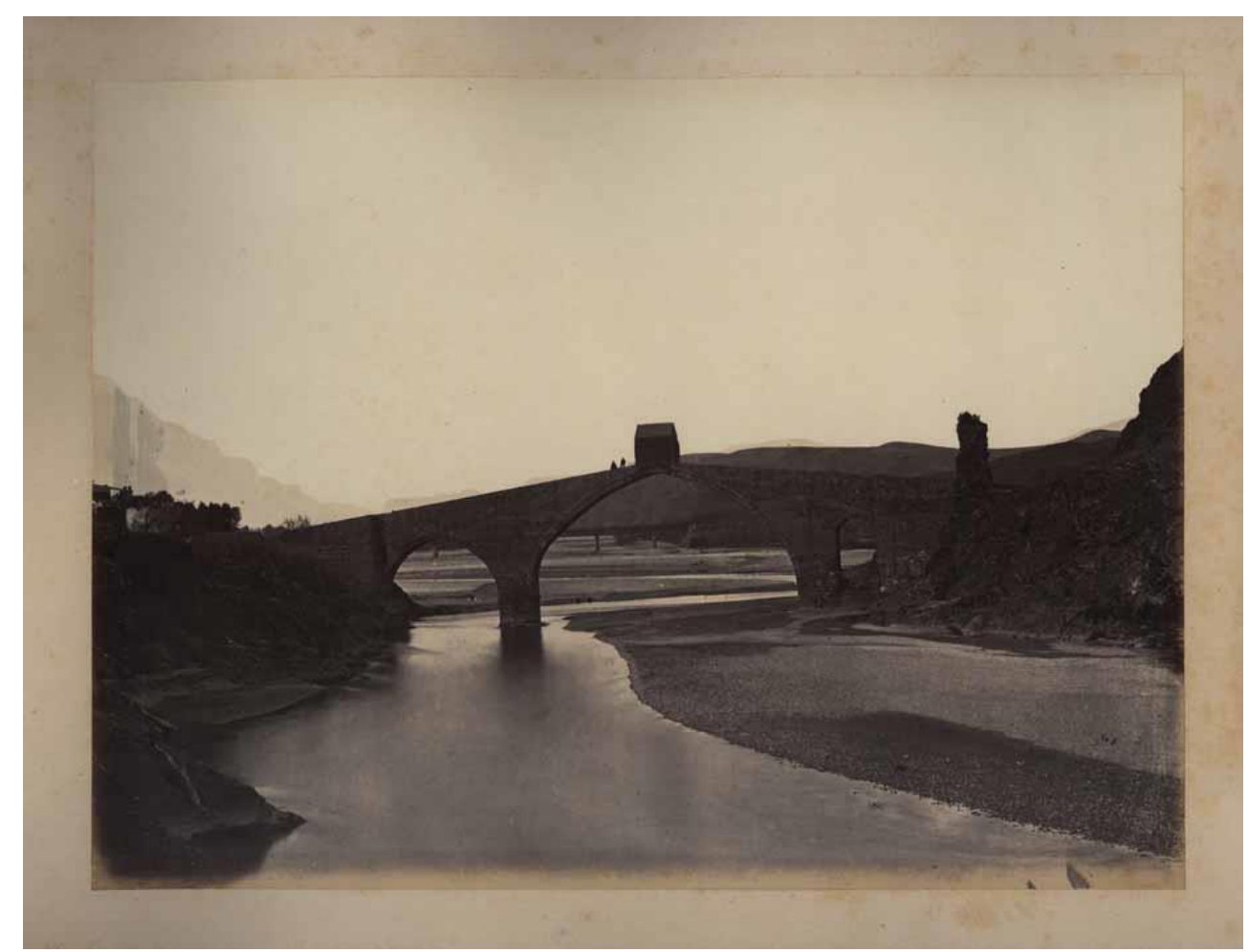

Fig. 5. MARTÍNEZ SÁNCHEZ, José. Puente del Diablo, Martorell, ca.1867, Papel a la albúmina, 25,9 x 34,2 cm. sobre cartulina 41 x 49,5 cm. Al pie de la fotografía nombre y dirección del fotógrafo impresos, a la izquierda: J. Martínez Sánchez Fotog. A la derecha: Puerta del Sol, 4 Madrid, Biblioteca Nacional de España, Signatura: 17-LF/133 (46), http://bdh-rd.bne.es/viewer.vm?id=0000047500. 
Aunque las dos vistas seleccionan una misma realidad: el puente y los elementos de su entorno, y ambas cuentan con un repertorio similar de atributos visuales, varía la sintaxis que ordena esos atributos: la composición. En la fotografía de Martínez Sánchez existe una unidad visual articulada por el movimiento aparente del río que nos conduce desde el primer hasta el medio plano donde se sitúa el puente, que parece un elemento más del paisaje, como si de un fenómeno de la naturaleza se tratase. La filosofía de la vista de Clifford es diferente: se presentan elementos inicialmente inconexos entre sí, o al menos de un modo no tan evidente, pero que al relacionarlos adecuadamente unos con los otros adquieren sentido y jerarquía dentro del marco, ofreciendo una imagen poderosa del puente. La destreza de Clifford reside en establecer buenas relaciones entre los diferentes elementos mediante la ubicación, el peso, la dirección, etc, para que entren en actividad y funcionen, trasladando al espectador la percepción arquitectónica (la función informativa) en combinación con una serie de factores estéticos que la carguen de significación plástica y la distingan de otros planteamientos más documentalistas.

Con el propósito de desentrañar estas dos fotografías, he realizado al efecto unos esquemas básicos ${ }^{15}$ de su construcción [fig.6]. No es un ejercicio que pretenda trasladar criterios compositivos de nuestro tiempo a fotografías del pasado, sino un propósito de demostrar (con todo merecimiento) la incipiente incorporación de códigos estéticos en las obras ejemplares de Clifford y Martínez Sánchez. Se observa como en los dos casos los puntos fuertes se sitúan dentro del área central del marco, pero con una mayor intencionalidad compositiva en el caso de Clifford, que organiza espacialmente una serie de elementos (de distinta naturaleza) que se suceden unos a otros articulando la fotografía. Un cambio en el orden jerárquico de estos elementos transformaría la imagen por completo, perdiendo su identidad.

\footnotetext{
${ }^{15}$ Conviene hacer alguna puntualización acerca del origen y del uso que en este trabajo se le da al concepto "esquema". En el ejercicio fotográfico es fundamental prescindir de todo aquello que distrae la atención sobre el elemento protagonista, pues no todo lo visto tiene el mismo peso en la realidad y en la fotografía. La cámara lo ve todo y democratiza la información, pero el cerebro, influido por nuestra memoria, suma todo ese conjunto de visiones y las recompone en modelos idealizados. El (buen) fotógrafo debe hacer con la fotografía lo mismo que hace su cerebro: filtrar la información para quedarse con lo que le interesa, solo con aquello que valoriza la arquitectura representada y ayuda a comunicarla. La utilización del esquema en este trabajo de investigación es precisamente la aplicación de ese filtro mental que es capaz de distinguir lo importante de lo superfluo. Consecuentemente, entiendo por esquema una representación básica de la fotografía cuya función ya no es descriptiva, y mucho menos narrativa, sino conceptual. Es un equivalente estructural de la realidad fotografiada que de un modo exclusivamente formal ayuda a una mejor comprensión de la construcción de la imagen fotográfica. Por lo tanto, no se trata de imitar una fotografía trasladando exactamente la posición y forma de cada elemento que la componen y la articulan, sino de eliminar lo irrelevante, tal como hace nuestro cerebro en el proceso de percepción visual, y llevarla a un grado de simplicidad formal mediante su traducción a geometrías elementales que nos permitan acercarnos a su verdadera raíz compositiva.
} 

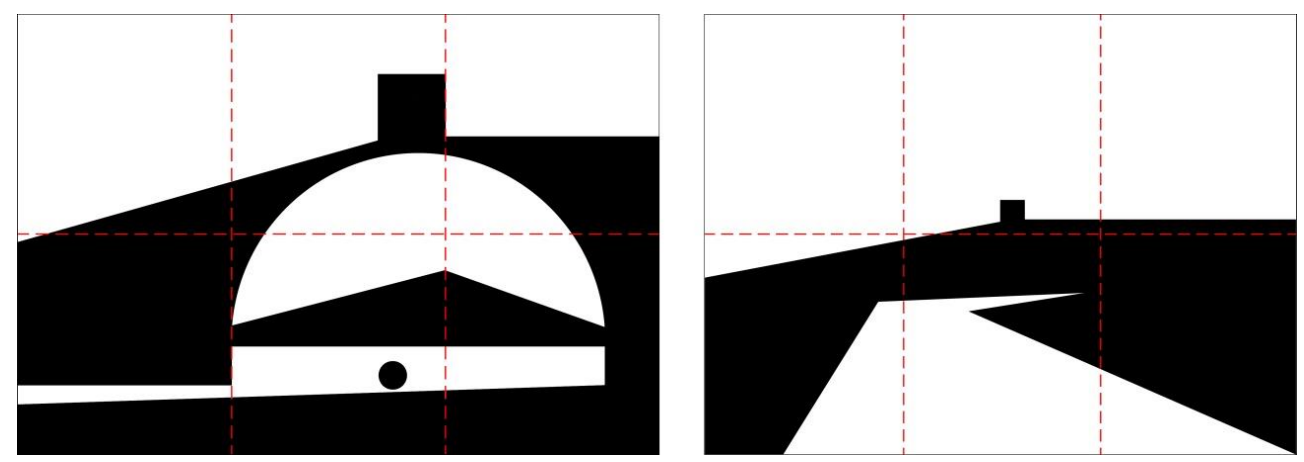

Fig. 6. Esquemas básicos de composición de Puente del Diablo que muestran la jerarquización de elementos de la fotografía de Clifford frente a la unidad visual de Martínez Sánchez con el río como vector direccional dominante.

Si en la vista del Puente de Diablo además de documentar, Clifford aporta un discurso propio en el que se detectan incipientes aportaciones estéticas, ofreciendo una versión personal del tema, en Puerta de Alcalá [fig.7] tenemos, desde mi punto de vista, un ejemplo de planteamiento de equivalencia directa: aspira a superar el simple documento trasladando el arte del monumento a su representación fotográfica, confiando en el poder de la belleza de la arquitectura como única fuerza que aporte sentido a la imagen. Para ello el autor busca el encuadre que mejor sirva para describir claramente el motivo, solucionado con un plano general que permite encuadrar la totalidad del volumen sin grandes perspectivas, pues prefiere acercar el edificio al espectador aislándolo, sin aportar información sobre el contexto urbano que lo rodea y evitando con ello desviar la atención del motivo protagonista. Cualquier observador atento puede reparar en la espléndida definición de la fotografía, que incluso nos permite leer los mensajes que anuncian los carteles publicitarios pegados sobre las pilastras pétreas del monumento. Por el contrario, la escasa capacidad de la cámara en la detección del tiempo provocaba indefiniciones en las personas y animales que se movieron durante la toma, apenas manifestándose en formas evanescentes. En la práctica fotográfica, fundamentalmente en su vertiente comercial, los elementos borrosos se consideraban imperfecciones o "manchas", y se buscaba la nitidez en toda la extensión del marco con el propósito (en vano) de igualar fotografía y realidad. Pero Clifford, en lugar de desechar estas imágenes -como haría una mayoría de colegas coetáneos, que veían más inconvenientes (confusión, ruido, barullo) que ventajas- las utiliza para introducir en el espacio plástico la sensación de vitalidad que caracteriza a la actividad urbana. 


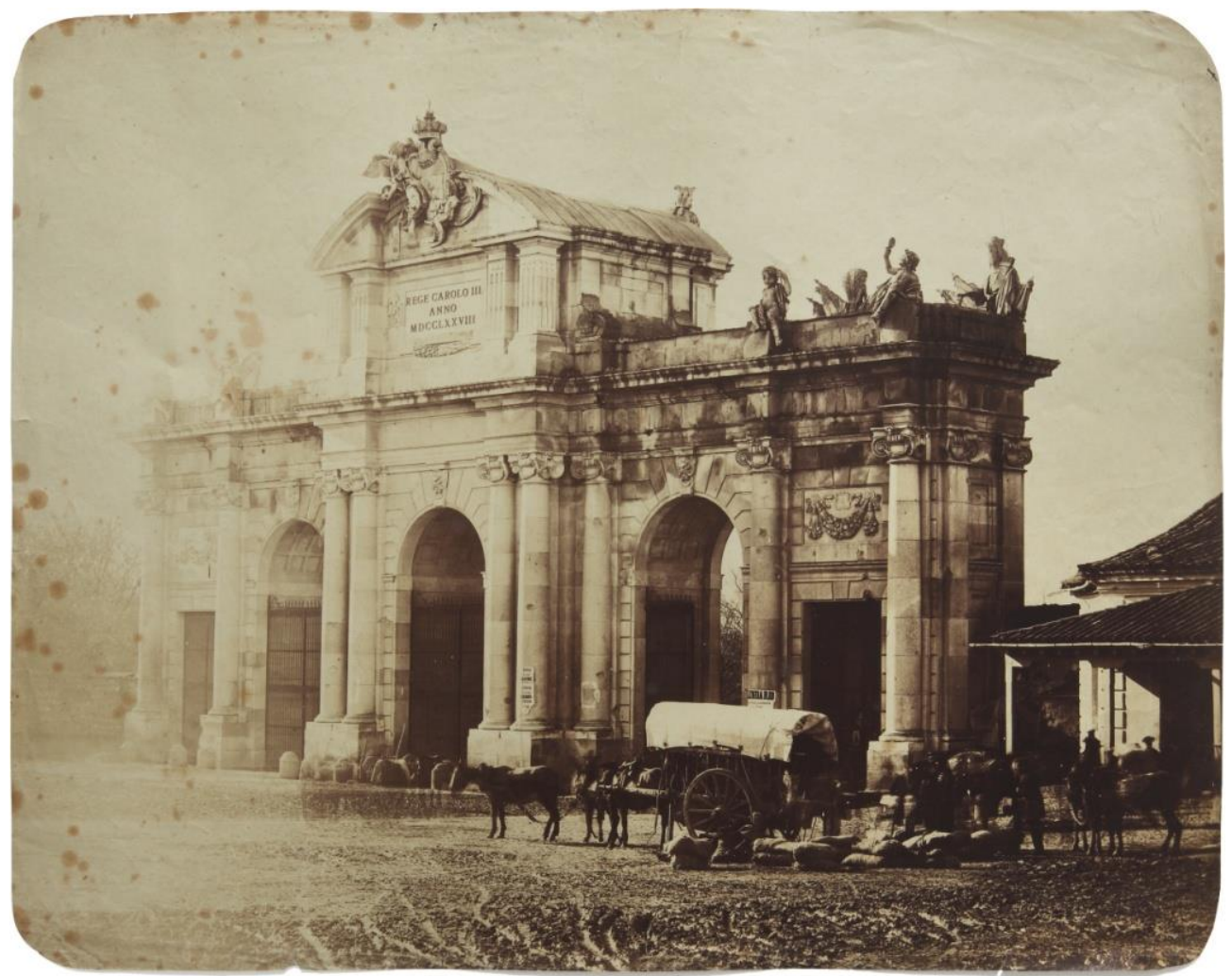

Fig. 7. CLIFFORD, Charles. Puerta de Alcalá, Madrid, ca.1858, Negativo cristal, Sólo papel fotográfico 33,3 x 42,6 cm., Colección Fierros.

Se desprende de este análisis formal y de la metodología gráfica aplicada, la consideración que Clifford y Martínez Sánchez tenían de la fotografía como algo más que un medio documental y propagandístico, abriendo nuevas vías de expresión que guiarán el desarrollo del lenguaje fotográfico de la arquitectura en la segunda mitad del siglo XIX. Se observa en el caso particular de Clifford una tendencia al aislamiento del motivo arquitectónico, presentándolo de forma clara y directa, restando elementos del contexto que puedan competir con él en protagonismo y generen consecuentemente una pluralidad de significados.

\section{Bibliografía}

BULLOUGH AINSCOUGH, R. (2015). "Globos y caballos" en Revista Internacional de la Imagen, Volumen 2, $\mathrm{N}^{\circ} 2$.

COLOMA MARTÍN, I. (1986). La forma fotográfica. A propósito de la fotografía española desde 1839 hasta 1939. Málaga: Universidad de Málaga y Colegio de Arquitectos. 
FONTANELLA, L. (1999). Clifford en España: un fotógrafo en la corte de Isabel II. Madrid: El Viso.

LÓPEZ MONDÉJAR, P. (2005). Historia de la fotografía en España. Fotografía y sociedad desde sus origenes hasta el siglo XXI, Barcelona: Lunwerg.

RIEGO AMÉZAGA, B. (2001). La construcción social de la realidad a través de la fotografía y el grabado informativo en la España del siglo XIX, Santander: Servicio de Publicaciones de la Universidad de Cantabria.

RODRÍGUEZ MOLINA, M.J. y SANCHÍS ALFONSO, J.R. (2014). Una nueva visión de la fotografía española: la obra de José Martínez Sánchez, 1807-1874, Valencia: Railowsky.

SCHARF, A. (1994), Arte y fotografía, Madrid: Alianza.

VILLAFAÑE GALLEGO, J. (1985). Introducción a la teoría de la imagen, Madrid: Pirámide.

Todas las reproducciones fotográficas de la colección Fierros publicadas en este artículo son inéditas y han sido realizadas por el autor entre 2016 y 2017 